\title{
Sobre algunos aspectos técnicos de la fluoración de las aguas de abastecimiento
}

\section{P L A N T E A M I N T O}

Al plantearse, por la Jefatura de Sanidad Provincial, la conveniencia de proceder a la fluoración de las aguas de abastecimiento de Pamplona, surgió la duda de si la adición del ion flúor en concentraciones del orden de 1 p.p.m. era fácilmente realizable y si ello podría producir efectos secundarios perjudiciales en la red de distribución.

Dado que no existe ningún abastecimiento en España, salvo creemos el de Rota, en que se proceda a una fluoración artificial, nos fue preciso recurrir a información extranjera, principalmente americana, para encontrar una contestación a ambos problemas. Otro posterior sería decidir qué compuesto de flúor era el más indicado para realizar la fluoración del modo más económico y eficaz.

La postura del Servicio fue, por tanto, meramente pasiva, porque la fluoración es una medida de profilaxis colectiva y su iniciativa debe corresponder a los responsables de la sanidad local; pero ante las noticias de que en algunas ciudades había problemas técnicos en las redes a partir de la puesta de servicio de fluoraciones, consideramos necesario tener un conocimiento lo más exacto posible de las dificultades que pudieran producirse.

\section{INFORMACION DE DIVERSAS LOCALIDADES EN QUE SE REALIZA}

\section{LA FLUORACION DEL AGUA DE ABASTECIMIENTO PUBLICO}

A continuación relacionamos las diversas informaciones que reunimos sobre el particular:

\section{Basilea}

En esta ciudad se adicionó fluor al agua desde 1962 sin que hayan tenido dificultades ni aumento de averías en la red. Utilizan fluosilicato sódico, y en los análisis que se llevan a cabo diariamente en diversos puntos de la red se comprueba la poca variación de la concentración del ion flúor sobre la considerada óptima de 1 p.p.m. 


\section{Embajada de E.E.U.U. en Madrid}

El agregado comercial de la embajada nos informó que existía en su país una oposición a la fluoración basada, principalmente, no en razones técnicas o médicas, sino democráticas, ya que esa medida supone imposición que para algunas personas no es lógica.

Nos aconsejaba en su carta entrar en contacto con la American Water Works Association y la American Dental Association.

\section{American Water Works Association}

Nos enviaron, en parte directamente y en parte a través del Instituto Eduardo Torroja, abundante información, entre la que figuraban estadísticas de la evolución de la fluoración, de las cuales se deducía que aunque la población total abastecida con agua fluorada iba en aumento, en bastantes lugares, (176ó no implantar la fluoración o suprimirla.

Figuraba también la estadística de referendums celebrados entre la población para decidir, de modo democrático, la entrada en vigor o no de la fluoración. Del total de 1.009 que se realizaron entre 1950 y 1967, en 441 ciudades ganaron los partidarios de la fluoración mientras que en 598 ciudades se decidió no implantar la fluoración o suprimirla.

Dato igualmente interesante de la información de la A. W. W. A. es el acuerdo de su Consejo de Directores, de fecha 29 de abril de 1951 y confirmado en 17 de junio de 1962, que dice textualmente:

"En comunidades en que se ha desarrollado una fuerte demanda pública y el procedimiento tiene el total apoyo de las sociedades médicas y dentales locales, de las autoridades locales y estatales de sanidad, y de los demás responsables de la salud pública, los Servicios y Compañías de Agua pueden correctamente participar en un programa de fluoración de los abastecimientos públicos".

Es interesante destacar la importancia que se da a la demanda pública, reflejo del criterio tan acusado de las libertades democráticas existentes en E.E.U.U., que ha llevado, en muchos casos, a resolver por vía electoral una cuestión que, en principio, pudiera parecer exclusivamente técnica.

Pese a que el acuerdo del Consejo de Directores de la A. W. W. A. era que por parte de los Servicios de Aguas no debiera ponerse inconvenientes a la fluoración, el hecho de que en tantas ciudades se hubiese suprimido, una vez instalado, nos hizo seguir profundizando en el tema para tratar de conocer las razones reales de la supresión.

\section{Mayer Goldberg, Corte Suprema de Chicago}

Entre la información que recibimos de la A. W. W. A. figuraba el sumario de un juicio celebrado en Chicago referente a la reclamación que por algunos habitantes de la ciudad se hizo al Ayuntamiento por haber introducido la fluoración.

En el sumario se estudian las diversas razones en contra de la fluoración, y en lo que a nosotros nos afecta se llegó a las siguientes conclusiones:

- Desde que se instala la fluoración (1956) hasta el proceso (1961) no se encontró ni corrosión ni aumento de averías. 
- La variación de la concentración de ión flúor en las 36 muestras que se examinan diariamente era lo suficientemente reducida como para que pudiera considerarse satisfactoria la dosificación.

\section{Departament of Water and Sewers of Chicago}

El juez Goldberg nos puso en comunicación con el Servicio de Aguas y Saneamiento de Chicago, donde nos informaron que hasta el momento (1971) y desde que en 1956 iniciaron la fluoración no habían tenido problemas de corrosiones, debidas a la adición de ácido hidrofluosilícico; pero que antes de proceder a una fluoración era conveniente asegurarse, sobre todo si se añadía una sustancia de carácter ácido, que no se alteraban las características del agua, de modo que ésta siguiese siendo no agresiva.

Esta contestación, unida a alguna otra que luego comentaremos, nos indicó las pruebas que deberíamos hacer antes de iniciar la fluoración.

\section{Riverhead N. Y.}

En la información recibida de la A. W. W. A. figuraba la referencia de que en Riverhead se había suprimido la fluoración. Así que nos dirigimos a Mr. John P. Riesdorph, perteneciente al Servicio de Aguas, preguntándole si las razones por haberla suprimido eran técnicas (corrosión en redes), médicas (posibles efectos nocivos al organismo o ineficacia del método), económicas, (gasto excesivo) o democráticas (oposición pública a un tratamiento colectivo obligatorio).

Mr. Riesdorph nos informó que la supresión había sido debida a:

- Ataque a las tuberías con formación de agua con herrumbre, hasta el extremo de que era imposible lavar la ropa. Esta situación desaparecía al suprimir la fluoración y volvía a presentarse cuando la reanudaron. Ante esta experiencia el Ayuntamiento resolvió la supresión definitiva de la fluoración. Una Compañía de ingeniería les asesoró que empleasen cal para ajustar el $\mathrm{pH}$ del agua hasta hacerla no agresiva.

- No apreciaron disminución de las caries (la fluoración funciona desde 1952 a 1963).

- Lo consideraron un gasto excesivo por el reducido porcentaje $(0,9 \%)$ que es bebido por los niños a los que beneficia la medida.

- Piensan que es una forma de medicación colectiva.

Mr. Riesdorph, que terminaba su carta diciendo: "No permita que nadie ponga fluor en su abastecimiento", nos puso en contacto con la editorial de "Fluoration News" de Hempstead N. Y.

\section{Fluoration News. Hempstead N. Y.}

Nos remitieron una abundantísima documentación, toda ella contraria a la fluoración (revistas bimestrales, folletos, recortes de periódicos, etc.). En la carta con que la acompañaban decía que es una equivocación añadir voluntariamente un producto químico al agua hoy, que, como consecuencia del proceso industrial, tanto el agua como el aire es- 
tán saturándose de productos químicos. Decían que la Public Health Service tomó el recomendar la fluoración como una decisión equivocada, y que sin hacer estudios posteriores, siguen diciendo que es correcta.

\section{Concord, New Hampshire}

Entre la documentación facilitada por Fluoration News, figuraba una carta del alcalde de Concord, en la cual decía: "que desde la puesta en marcha de la fluoración habían tenido corrosiones en tanques y tuberías de cobre y hierro, tanto en tuberías principales como en acometidas e instalaciones interiores de edificios".

Una firma de ingeniería les aconsejó empleasen hidróxido sódico para elevar el $\mathrm{pH}$, con lo que desaparecerían los efectos perjudiciales que habían surgido a consecuencia de la adición al agua de compuestos de flúor.

\section{Water Supply and Pollution Control Commission. State of New Hampshire}

Para confirmar lo expuesto en la carta del alcalde de Concord nos dirigimos al Water Supply and Pollution Control Commission del Estado de New Hampshire. Nos contestaron diciendo: "En el tiempo que duró la fluoración (1952-1959) no hubo ningún problema, ni técnico ni médico, y que la mejora dental de los niños fue apreciable.

Se suprimió la fluoración a consecuencia de un referéndum propuesto por un grupo que objetó la fluoración, pero las restantes ciudades del Estado siguen fluorando sus abastecimientos.

Como puede verse esta contestación está en clara contradicción con la anterior.

\section{Otras informaciones}

Tuvimos correspondencia con los responsables de Sanidad de Knoxville (Tenessee). Nos informaron de que en numerosas ciudades habían encontrado concentraciones muy elevadas (del orde nde 6.000 p.p.m.) en muestras extraídas de las tuberías, así como de que en diversas ciudades tuvieron que cambiar longitudes importantes de tuberías a causa de corrosiones producidas por los compuestos del flúor.

En el mismo sentido fue la información recibida de Seattle (Wasghinton), facilitado por el Dr. Exner, uno de los testigos del juicio de Chicago.

Del Estado de New Jersey recibimos información de la ciudad de Boonton, donde no realizan la fluoración por no tener un informe claro sobre sus ventajas; así como del Departamento de Protección ambiental. Este último organismo nos informó que, a su juicio, es una práctica aconsejable y fácil de realizar sin que produzca perjuicios en las redes.

\section{INTERPRETACION DE LA DOCUMENTACION}

De la documentación recibida se desprende - a pesar de las contradiciones existentes entre unas y otras informaciones- que, como consecuencia de la fluoración, en diversas ciudades hubo problemas derivados de la acidez del agua, los cuales se corrigieron aña- 
diendo un álcali hasta lograr el $\mathrm{pH}$ apropiado; es decir, que el ataque a las tuberías no era debido al ion flúor, sino a la alteración del $\mathrm{pH}$ causada por el compuesto del flúor empleado (generalmente ácido fluosilícico).

No parece, por tanto, que ello pueda ser causa de una oposición a la fluoración, sino que antes de iniciarse se debe proceder a realizar análisis con el agua de que se disponga y el producto que se haya decidido emplear, estudiando el grado de agresividad del agua resultante, así como las medidas correctoras.

Tampoco parece que existan dificultades para mantener la concentración del ión flúor en la concentración correcta, tal como se desprende de los análisis de Basilea y Chicago.

\section{ANALISIS EFECTUADOS}

Para estudiar, en nuestro caso, la variación del pH del agua a causa de la adición de compuestos del flúor se procedió, por los laboratorios oficiales de Pamplona, a llevar a cabo una serie de ensayos utilizando diversos compuestos de flúor (fluoruro sódico, ácido fluosilícico, fluosilicato amónico fluosilicato sódico, y difluoruro amónico) y en concentraciones muy variables de ion flúor, llegándose al resultado que en valores del órden de 1-2 p.p.m. no había, en ningún caso, en el agua de nuestro abastecimiento, alteraciones de $\mathrm{pH}$, produciéndose éstas cuando la concentración era del orden de uno por mil.

\section{COMPUESTO A EMPLEAR}

En la elección del compuesto a emplear influye apreciablemente los precios de cada producto en el lugar y tiempo de su utilización, así como las facilidades de suministro, calidad, etc.

A título orientativo relacionamos los costos, por $\mathrm{kg}$ de ion flúor adicionado al agua, calculados en noviembre de 1971, época en que se hizo este trabajo.

Todos los precios proceden de una fábrica dedicada a la fabricación de compuestos de flúor. Es fácil adquirir fluosilicato sódico a precio más económico, ya que es un subproducto de determinadas fábricas de abonos químicos; pero pensamos que un subproducto, además de contener otras sustancias que pueden no ser beneficiosas, es difícil garantizar la constancia de su riqueza, por lo cual no pensamos sea apropiado para emplear en un tratamiento que requiere una gran precisión en la dosificación.

\begin{tabular}{|c|c|c|c|c|c|c|c|c|c|}
\hline Compuesto & Fórmula & $\begin{array}{c}\text { Riqueza } \\
(\%)\end{array}$ & $\begin{array}{c}\text { Precio } \\
\text { (Ptas./kg) }\end{array}$ & $\begin{array}{c}\text { Contenido } \\
\text { del }\end{array}$ & $\begin{array}{l}\text { en } \\
\text { comp }\end{array}$ & $\begin{array}{l}\text { F de } 1 \\
\text { puesto }\end{array}$ & kg & $\begin{array}{l}\text { Precio de } \\
\text { (con \% } \\
\text { de riquez.) }\end{array}$ & $\begin{array}{l}1 \text { kg de } \mathbf{F} \\
\text { (con } 100 \% \\
\text { de riquez.) }\end{array}$ \\
\hline Acido fluorhídrico & FH & 70 & 28 & $19 / 20$ & $=$ & 0,950 & $\mathrm{~kg}$ & 29,47 & 42,10 \\
\hline Fluoruro sódico & $\mathrm{FNa}$ & 98 & 28 & $19 / 42$ & $=$ & 0,452 & $"$ & 61,95 & 63,21 \\
\hline Fluoruro amónico & $\mathbf{F}\left(\mathrm{NH}_{4}\right)$ & 98 & 44 & $19 / 37$ & $=$ & 0,514 & $"$ & 85,60 & 87,34 \\
\hline Acido fluosilícico & $\mathrm{F}_{6} \mathrm{SiH}_{2}$ & 25 & 20 & $114 / 144$ & $=$ & 0,792 & $"$ & 25,25 & 101,60 \\
\hline Fluosilicato amónico & $\mathrm{F}_{6} \mathrm{Si}\left(\mathrm{NH}_{4}\right)_{2}$ & 97 & 27 & $114 / 178$ & $=$ & 0,640 & $"$ & 42,19 & 43,50 \\
\hline Fluosilicato de sodio & $\mathrm{F}_{6} \mathrm{SiNa}_{2}$ & 98 & 24 & $114 / 188$ & $=$ & 0,606 & $"$ & 39,60 & 40,41 \\
\hline Bifluoruro amónico & $\mathrm{F}_{2} \mathrm{HNH}_{4}$ & 98 & 45 & $38 / 57$ & $=$ & 0,666 & $"$ & 67,56 & 68,95 \\
\hline
\end{tabular}


Para tener una idea del costo de reactivos vamos a considerar que se trata de 150.000 habitantes con una dotación de $300 \mathrm{l} / \mathrm{hab}$./día, que supone un caudal de:

$150.000 \times 300=45.000 \mathrm{~m}^{3} /$ día.

Con una dosis de $1 \mathrm{~g} / \mathrm{m}^{3}$ serán precisos:

$0,001 \times 45.000=45 \mathrm{~kg}$ de ion $\mathrm{F} /$ día .

Con lo que el gasto diario de reactivo será para cada compuesto:

\begin{tabular}{lrr}
\hline Compuestos & Casto diario & Costo anual \\
\hline $\mathrm{FH}$ & $1.894,50$ & $691.492,50$ \\
$\mathrm{FNa}$ & $2.844,45$ & $1.038 .224,25$ \\
$\mathrm{~F}\left(\mathrm{NH}_{4}\right)$ & $3.930,30$ & $1.434 .559,50$ \\
$\mathrm{~F}_{6} \mathrm{SiH}_{2}$ & $4.545,00$ & $1.658 .925,00$ \\
$\mathrm{~F}_{6} \mathrm{Si}_{\left(\mathrm{NH}_{4}\right)_{2}}$ & $1.957,50$ & $714.487,50$ \\
$\mathrm{~F}_{6} \mathrm{SiNa}_{2}$ & $1.818,45$ & $663.734,25$ \\
$\mathrm{~F}_{2} \mathrm{HNH}_{4}$ & $3.102,75$ & $1.132 .503,75$ \\
\hline
\end{tabular}

Vemos que el gasto anual es bastante elevado, con diferencias notables de unos compuestos a otros, por lo que debe estudiarse detenidamente la eleción del compuesto a emplear.

Empleando bifluoruro amónico, producto de costo intermedio, la repercusión por $\mathrm{m}^{3}$ de agua es:

$$
\frac{3.102,75}{45.000}=0,07 \text { ptas. } / \mathrm{m}^{3} \text {. }
$$

A este importe hay que añadir la amortización de la instalación personal, etc., con lo que el costo total será del orden 0,10 pesetas por $\mathrm{m}^{3}$ de agua fluorada.

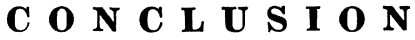

Como resumen de la experiencia reunida podemos decir que el acuerdo del Consejo de Directores de la A. W. W. A. es muy acertado, aunque antes de iniciar la fluoración es conveniente realizar ensayos para comprobar que el compuesto de flúor que se decida utilizar no alterará las características de agresividad del agua.

No parece que haya dificultades en mantener la concentración del ion flúor en la dosis deseada.

El costo de la fluoración, calculado a precios de 1971 , supone unas $0,10 \mathrm{ptas} . / \mathrm{m}^{3}$. 